\title{
Preparation and Characteristics of Starch Esters and Its Effects on Dough Physicochemical Properties
}

\author{
Shuangqi Tian, Yimei Chen, Zhicheng Chen $\mathbb{D}^{D}$, Yingqi Yang, and Yanbo Wang \\ College of Food Science and Engineering, Henan University of Technology, Zhengzhou 450001, China \\ Correspondence should be addressed to Zhicheng Chen; chen_1958@163.com
}

Received 4 June 2018; Revised 7 August 2018; Accepted 14 August 2018; Published 12 November 2018

Academic Editor: Ekaterini Moschopoulou

Copyright (C) 2018 Shuangqi Tian et al. This is an open access article distributed under the Creative Commons Attribution License, which permits unrestricted use, distribution, and reproduction in any medium, provided the original work is properly cited.

As a recyclable natural material, starch is an important raw material in food and other fields. The native starch by esterification could improve the performance of the original starch and expand its range of application. This article reviews the preparation process of acetylated distarch adipate, starch sodium octenylsuccinate, starch acetate, hydroxypropyl starch, and starch phosphate and research into the influence of starch esters on dough. At the same time, it forecasts the trend of starch esters and application prospect in the future research.

\section{Introduction}

Starch is a natural, renewable, biodegradable polymer and rich in resources that are widely found in a variety of plants. Many of its unique physicochemical properties are extensively applied in food and other industries [1,2], but most of the native starch itself cannot be used directly [3]. After modification, the starch properties are improved and can meet the requirements of multilevel processing.

Esterification is one of the effective ways of denaturation, and the starch can be modified by physical, chemical, or enzymatical methods which are effectively applied in food, textile, papermaking, petrochemical, and pharmaceutical industries depending on its different properties. The application of starch ester in foreign countries was earlier, and large-scale industrial productions have been achieved. Some starch esters for food applications mainly include starch acetate, acetylated distarch adipate, starch sodium octenylsuccinate, monostarch phosphate, distarch phosphate, phosphated distarch phosphate, acetylated distarch phosphate, hydroxypropyl distarch phosphate, and hydroxypropyl starch in the US and EU countries [4, 5]. Although the researches are carried out relatively late in China, the researches and development of starch esters has matured gradually in the past two decades. At present, starch esters as food additives mainly include phosphate distarch, acetate starch, sodium starch phosphate, acetylated distarch adipate, phosphorylated distarch phosphate, acetylated distarch phosphate, and hydroxypropyl distarch phosphate in China [6]. Since many scholars had already researched the preparation process, the synthesis technology has mainly focused on increasing the degree of substitution (DS) which determined the application direction of esterified starch $[7,8]$. The following is a summary of common organic acid starch esters and inorganic acid starch esters (Table 1).

\section{Preparation of Starch Esters and Properties}

2.1. Acetylated Distarch Adipate. Acetylated distarch adipate (ADiSP) is a cross-linked composite modified starch obtained by esterification of starch with adipic acid and acetic anhydride. The production has the characteristics of crosslinked and esterified starch and has thermal stability, high shear resistance, and acid resistance. Acetylated distarch adipate could be used as a thickener, stabilizer, and binder in the food industry [9]. Acetylated distarch phosphate is a modified starch used in some baby foods. The bioavailability of ADiSP and a native (unmodified) starch was evaluated in 20 normal infants and 21 toddlers aged 8-24 mo with chronic nonspecific diarrhea [10].

Acetylated, cross-linked, and pregelatinized cassava starches were produced in a single-screw extruder with 
TABle 1: Preparation techniques of different starch esters and their properties with applications.

\begin{tabular}{|c|c|c|c|}
\hline Types & Preparation & Properties & Applications \\
\hline Esterification & $\begin{array}{c}\text { Starch acetate-esterification with acetic } \\
\text { anhydride or vinyl acetate } \\
\text { Acetylated distarch } \\
\text { adipate-esterification with acetic } \\
\text { anhydride and adipic anhydride } \\
\text { Starch sodium } \\
\text { octenylsuccinate-esterification by } \\
\text { octenylsuccinic anhydride }\end{array}$ & $\begin{array}{l}\text { Lower gelatinization temperature and } \\
\text { retrogradation, lower tendency to form } \\
\text { gels and higher paste clarity }\end{array}$ & $\begin{array}{c}\text { Used in refrigerated and frozen foods, } \\
\text { as emulsion stabilizers and for } \\
\text { encapsulation }\end{array}$ \\
\hline Cross-linking & $\begin{array}{l}\text { Monostarch phosphate-esterification } \\
\text { with orthophosphoric acid, or sodium or } \\
\text { potassium orthophosphate, or sodium } \\
\text { tripolyphosphate } \\
\text { Distarch phosphate-esterification with } \\
\text { sodium trimetaphosphate or } \\
\text { phosphorus oxychloride } \\
\text { Phosphated distarch } \\
\text { phosphate-combination of treatments } \\
\text { for monostarch phosphate and distarch } \\
\text { phosphate }\end{array}$ & $\begin{array}{l}\text { Higher stability of granules towards } \\
\text { swelling, high temperature, high shear, } \\
\text { and acidic conditions }\end{array}$ & $\begin{array}{c}\text { Used as viscosifiers and texturizers in } \\
\text { soups, sauces, gravies, bakery, and } \\
\text { dairy products }\end{array}$ \\
\hline $\begin{array}{l}\text { Dual } \\
\text { modification }\end{array}$ & $\begin{array}{c}\text { Acetylated distarch } \\
\text { phosphate-esterification by sodium } \\
\text { trimetaphosphate or phosphorus } \\
\text { oxychloride combined with } \\
\text { esterification by acetic anhydride or } \\
\text { vinyl acetate } \\
\text { Hydroxypropyl distarch } \\
\text { phosphate-esterification by sodium } \\
\text { trimetaphosphate or phosphorus } \\
\text { oxychloride combined with } \\
\text { etherification by propylene oxide }\end{array}$ & $\begin{array}{l}\text { Stability against acid, thermal and } \\
\text { mechanical degradation, and delayed } \\
\text { retrogradation during storage }\end{array}$ & $\begin{array}{c}\text { Used in canned foods, refrigerated and } \\
\text { frozen foods, salad dressings, } \\
\text { puddings, and gravies }\end{array}$ \\
\hline Etherification & $\begin{array}{l}\text { Hydroxypropyl starch-esterification } \\
\text { with propylene oxide }\end{array}$ & $\begin{array}{l}\text { Improved clarity of starch paste, } \\
\text { greater viscosity, reduced syneresis, } \\
\text { and freeze-thaw stability }\end{array}$ & $\begin{array}{l}\text { Used in wide range of food } \\
\text { applications such as gravies, dips, } \\
\text { sauces, fruit pie fillings, and puddings }\end{array}$ \\
\hline
\end{tabular}

different moisture contents $(180,220$, and $260 \mathrm{~g} / \mathrm{kg})$, different adipic acetic mixed anhydride concentrations $(4,11$, and $18 \mathrm{~g} / \mathrm{kg}$ ) and screw speeds $(100,130$, and $160 \mathrm{rpm})$. The acetylation, cross-linking, and pregelatinization steps increased the cold viscosity, water absorption index, and gel hardness and reduced the gel cohesiveness, paste clarity, and retrogradation of the starches produced. Products manufactured under less severe operational conditions $(260 \mathrm{~g} / \mathrm{kg}$ moisture and $100 \mathrm{rpm}$ screw speed), and at higher reagent concentration $(18 \mathrm{~g} / \mathrm{kg})$, had the major group of functional characteristics preferred for puddings, instantaneous desserts, and foods subjected to low-temperature storage. Using $260 \mathrm{~g} / \mathrm{kg}$ moisture, $11 \mathrm{~g} / \mathrm{kg}$ reagent concentration, and a screw speed of $160 \mathrm{rpm}$, the starch products gave high clarity and no syneresis and could be used in fruit pie fillings, soups, and canned foods [11].

Acetylated tapioca distarch adipate was prepared by acetylation and cross-linking reaction using tapioca starch as a raw material and a mixture of acetic anhydride and adipic acid as acetalation and cross-linking agent, respectively, and by a wet approach. The impact of modification factors such as the amount of acetic anhydride and adipic acid, $\mathrm{pH}$ value, and reaction time on the esterification reactions was systematically studied. The optimum conditions required for preparation of acetylated tapioca distarch adipate were $0.050 \%$ adipic acid, $3 \%$ acetic anhydride, $\mathrm{pH} 8.0$, and $90 \mathrm{~min}$. The peak viscosity and cold viscosity of the acetylated tapioca distarch adipate were $1141 \mathrm{BU}$ and $1695 \mathrm{BU}$, respectively, which were higher than those of native tapioca starch. The gelatinization temperature of acetylated tapioca distarch adipate decreased, but viscosity stability was enhanced. The shearing resistance and freeze-thaw stability were much improved, but the transparency decreased [12, 13].

\subsection{Starch Sodium Octenylsuccinate. Starch sodium octe-} nylsuccinate is one of the most widely used starch esters. It was first successfully synthesized by Caldwell and Wurzburg in the United States and was patented in 1953 [14]. Starch sodium octenylsuccinate is one of the food additives used earlier and a sort of safe and reliable emulsifier thickener. When the octenylsuccinic anhydride reacts with the starch, the ring of the anhydride is opened under alkaline conditions: one end of which combines with sodium hydroxide to form a sodium salt and the other end reacts with the starch and removes one molecule of water. The entire reaction $\mathrm{pH}$ is continuously reduced as the reaction proceeds, so it is continuously neutralized with an alkaline solution to ensure $\mathrm{pH}$ 
of the entire reaction system, so that the reaction proceeds efficiently. Since the esterification reaction and the hydrolysis reaction proceed simultaneously, the esterification reaction predominates at the beginning of the reaction phase, and the reaction proceeds to the esterification reaction; when the reaction reaches a certain time, the hydrolysis reaction will be dominant due to the decrease of the substrate concentration, so the reaction time is not as long as possible, so you must control the reaction time. There are mainly wet, dry, and physical extrusion methods for preparing starch octenylsuccinate [15].

The specific operation of the synthesis is to dispose a certain concentration of suspension in the reaction vessel and use a $2 \% \mathrm{NaOH}$ solution to adjust the $\mathrm{pH}$ of the starch solution. The treated starch sodium octenylsuccinate was slowly added to the mixed solution in portions while keeping the system $\mathrm{pH}$ at $8.0 \pm 0.2$ during the addition. At the end of the reaction, the $\mathrm{pH}$ of the reaction mixture was again adjusted to 6.5 using $2 \% \mathrm{HCl}$. The resulting product was washed and centrifuged, and it was dried three times in an oven at $45^{\circ} \mathrm{C}$ and dried to obtain starch sodium octenylsuccinate [10]. Therefore, Yoshimura et al. [16] used the organic phase method to synthesize starch octenylsuccinate using 4-dimethylaminopyridine (DMAP) as an esterification catalyst and dimethyl sulfoxide as a solvent.

The dry method mixes the starch with the alkali, sprays the water to $25 \%$ water content of the starch, sprays the anhydride diluted with the organic solvent, reacts after mixing, or the starch is first suspended in a solution with a mass fraction, and then filtered until the starch is dried to the required moisture and sprayed into an anhydride diluted with an organic solvent and heated in dry mixer. This method allows the process to be simple, highly efficient, and low cost but nonuniform and easily leads to local violent reaction [17].

In the conventional wet method (aqueous phase method), the degree of substitution and the efficiency of esterification depend on the type of starch and the reaction parameters, and they are also affected by the surface structure of the starch granules. Due to the low solubility of starch sodium octenylsuccinate in water, the esterification reaction with starch mainly occurs on the surface of the particles, and the problems such as uneven distribution of acid anhydride and poor reaction efficiency occur easily. On the other hand, the use of sodium hydroxide, pyridine, and anhydride at high temperature often leads to the production of other by-products in the process of chemical reaction [18]. In recent years, through the improvement of traditional synthetic technology, it has sought to achieve higher efficiency and degree of substitution in a shorter time. The main methods involved mechanical activation, microwaveassisted, and enzymatic methods. The enzymatic method can realize the reaction under mild conditions and is environmentally friendly. In addition, due to the high efficiency of the enzyme, the reaction rate can be greatly promoted and the product quality can be also improved. The lipase-conjugated esterification can sharply drop the reaction time from several hours to $30 \mathrm{~min}$, and it makes the bioenzymatic method technically feasible in the large-scale production of starch sodium octenylsuccinate [19]. Xu et al. [20] researched high-speed shear-assisted OS-starch synthesis and characterized its modified properties. Compared with the control sample, the starch's DS increased from 0.0182 to 0.0202 , and thermal stability, transparency, and freeze-thaw stability improved likewise. High-speed shear attenuates the crystalline regions of starch granules without changing the type of crystallization, while the cavitation effect increases the reaction area by destroying the surface of the granules, and also promotes the reduction in droplet size and uniformity of distribution of starch sodium octenylsuccinate, making more OS groups induced into the inner regions of the starches [21].

2.3. Starch Acetate. Starch acetate is obtained by introducing an acetyl group into a hydrogen atom of the hydroxyl group on glucose. Starch acetate could be divided into high (1.5-3), medium (0.2-1.5), and low degree of substitution (0.01-0.2). Low-substituted acetylated starch has been widely used in the food industry as a kind of thickener or stabilizer. However, the acetylated starch with medium and high degree of substitution had high solubility in acetone and chloroform and was mainly used for research and development of thermoplastic materials and biodegradable materials [22].

Preparation of starch acetate esterification agent mainly covered acetic anhydride, vinyl acetate, vinyl chloride, ketene, and so on. Chemical synthesis generally preferred acetic anhydride and vinyl acetate as esterifying agents. In current commercial production, most of the synthesis routes chose $\mathrm{NaOH}$ as a catalyst to react starch and anhydride in an alkaline aqueous suspension [23].

The starch suspension was configured and shaken at $1500 \mathrm{rpm}$ for $1 \mathrm{~h}$ at $25^{\circ} \mathrm{C}$. The $\mathrm{pH}$ of the starch suspension was adjusted to 8.0 with $3 \% \mathrm{NaOH}$, and acetic anhydride was slowly added. The $\mathrm{pH}$ was always maintained between 8.0 and 8.4 during the addition. After complete addition of acetic anhydride, the reaction was allowed to continue for 15 minutes. The $\mathrm{pH}$ was adjusted to 4.5 with a $0.5 \mathrm{~mol} / \mathrm{L} \mathrm{HCl}$ solution, and the suspension after the reaction was stopped, centrifuged for 3 minutes, washed successively with ethanol, and finally dried in an oven at $40^{\circ} \mathrm{C}$ to give starch acetate [24].

Tupa et al. [25] used a novel organic acid catalyzed heterogeneous approach to synthesize starch esters, and it features the use of a nontoxic green catalyst tartaric acid in the absence of the solvent. Volkert et al. used different synthetic routes to compare the mechanical properties of starch acetate prepared by adding three different activators of acetic acid, sodium hydroxide, and potassium carbonate [26]. Colussi et al. made different degrees of acetylation of high, medium, and low amylose rice starch. The results showed that rice starch with the low amylose content was more easily acetylated, and DS is higher than that of the high and medium amylose under the same circumstances at different reaction times [27].

The physical auxiliary methods for preparing starch acetate mainly include microwave-assisted synthesis and 
mechanical activation. Microwave processing has achieved comprehensive researches over the past decade. Microwave heating can overcome the limitations of time-consuming and low substitution in single acetylation. Under the condition of keeping starch granules intact, it causes surface roughness and internal destruction of particles promoting the degree of acetylation [28]. The pulsed electric field (PEF) that regard as a new technique has been similarly applied to the acetylation process. Hong et al. researched that PEF treatment was able to enhance the esterification rate in a short period of time under appropriate conditions. This was due to the potential difference and the alterant direction of the electric field. The PEF system would accelerate the migration rate and direction of the reaction ions, and the effective collision between ions, which expedited the reaction rate and increased the DS. Therefore, moderate starch concentration $(35 \%)$ and high electric field strength were more conducive to the formation of high DS starch acetate [29].

2.4. Hydroxypropyl Starch. The reaction of starch with the etherifying reagent, propylene oxide, results in the introduction of the hydroxypropyl group onto the polymeric chain of starch. The alignment of polymers that causes a change in the structure of the food product, leads to an opaque, gelled, and/or chunky texture with "weeping" of liquid from the gel. This is termed as retrogradation and is undesirable in many food applications [30]. The etherification process is mainly done to inhibit retrogradation [31]. The reactive nature of propylene oxide is due to its highly strained three-membered epoxide ring. Bond angles in the ring average $60^{\circ} \mathrm{C}$ resulting in a very unstable (reactive) molecule.

In substitution reactions by etherification, the starch molecule should first be activated to make the O-H bond nucleophilic and to facilitate the formation of starch- $\mathrm{O}^{-}$. Alkaline reagents in this regard are excellent as catalysts. This is followed by reaction of starch- $\mathrm{O}^{-}$and propylene oxide which results in bimolecular substitution producing hydroxypropyl starch [32]. The efficiency of hydroxypropylation is greatly influenced by the reagents used. Etherification occurs mainly in the amorphous region of the starch granule. It is reported to affect the conformation of amylose molecules, and holes are known to appear at the surface of the granule [33]. The reaction efficiency is defined as the percentage of the reagent reacted or substituted upon starch. The remaining reagent is consumed to form byproducts. The efficiency depends upon the diffusion or penetration of alkali catalyst and etherifying agent into starch granules and the chances of collisions of the starch alcoholate nucleophile with the propylene oxide molecule. The elevated temperature of reaction helps in diffusion of alkaline catalyst and penetration of etherifying reagent more readily into the reaction point inside the starch granule and thus economises the reagent consumption.

Preparation of hydroxypropyl starch from a variety of cereal starch sources such as rice [34], wheat $[35,36]$, corn [37], tuber starch sources like potato [38], and legume starch sources e.g., field pea [39] has been reported. A number of patented processes have been developed for the preparation of low-substituted hydroxyalkyl starch ethers in the aqueous phase. High levels of substitution can be obtained in granular starch by using nonaqueous media or in dry conditions [40].

Kim et al. prepared hydroxypropyl starch and compared the effects of glycerin, sorbitol, and xylitol on the starch film. It was found that $20 \%$ glycerol was the best plasticizer. After hydroxypropylation, the brittleness of the starch film decreases [41]. Hydroxypropyl gluten corn starch was prepared by using propylene oxide as an etherifying agent, and it was found that the thermal stability, acid resistance, and transparency of the starch were enhanced as the degree of substitution increased. Hydroxypropyl starch has a hydroxypropyl group attached to it, which hinders the hydrogen bond polymerization of starch molecules, which causes the starch gelatinization temperature to decrease, the stability of the paste liquid to be enhanced, the transparency to be improved, the mechanical strength of the starch film to increase, and the barrier property to be enhanced [42].

2.5. Starch Phosphate. Starch phosphate is an esterified starch obtained after phosphorylation. At present, there were mainly dry, wet, and semidry methods for the preparation of starch phosphate at home and abroad. In the dry process, a certain ratio of phosphate and urea solution was adjusted to $\mathrm{pH}$, and then uniformly sprayed into the dry starch to reduce the moisture in the drying oven to heat the reaction to obtain the starch phosphate. The wet process adopted in traditional industrial production allows phosphorylating agents (orthophosphate, metaphosphate, phosphorus oxychloride, etc.) to be added to the starch suspension or reacted in organic solvents. Landerito and Wang [43] researched that phosphorylation could increase starch viscosity and water binding capacity. Conventional phosphorylation could produce monosubstituted phosphate monoester starch or cross-linked phosphodiester starch. The type and ratio of the product depended mainly on the phosphorylating agent used, concentration, $\mathrm{pH}$, and reaction conditions. In aqueous media, phosphate monoester starch was easily formed under mild acid conditions and cross-linked phosphodiester starch was formed under alkaline conditions $[44,45]$.

For wet synthesis, sodium phosphate was first dissolved in deionized water, the $\mathrm{pH}$ was adjusted to 6 or 8.5 with $10 \mathrm{M}$ $\mathrm{NaOH}$, and water was added to $100 \mathrm{ml}$. The appropriate amount of starch is added, stirred until it was viscous, and allowed it to equilibrate for 4 hours. The mixture was dried in an oven at $50^{\circ} \mathrm{C}$ overnight and then reacted at $140^{\circ} \mathrm{C}$ for $4 \mathrm{~h}$. Unreacted sodium phosphate was extracted with a hot aqueous ethanol solution, and the precipitated starch was collected. The distilled water was washed and dried several times to obtain phosphate monoester starch [46]. Przetaczek-Roznowska and Fortuna [47] preparated starch phosphates under alkaline conditions with a mixture of sodium tripolyphosphate, sodium trimetaphosphate, sodium sulfate, and pumpkin starch and studied the effect of 
different esterification temperatures $\left(115^{\circ} \mathrm{C}\right.$ and $\left.145^{\circ} \mathrm{C}\right)$ and duration of phosphorylation on starch gelatinization characteristics and rheology. Although the wet process has continued for many years and the technology is mature, it had the disadvantages of wastewater pollution and high energy consumption and high cost in industrial production.

In recent years, semidry preparation has become a research hotspot. Lars Passauer et al. [45] adjusted the $\mathrm{pH}$ of sodium dihydrogen phosphate and disodium hydrogen phosphate solution to $\mathrm{pH} 5$ by sodium hydroxide, added starch to the mixture, stirred, and vacuum-filtered. After that, the filter cake was crushed at $55^{\circ} \mathrm{C}$ and dried for $24 \mathrm{~h}$. The homogenized mixture was dried again at $65^{\circ} \mathrm{C}$ for $90 \mathrm{~min}$ and reacted at $150^{\circ} \mathrm{C}$ for $3 \mathrm{~h}$. After cooling to room temperature, unreacted phosphate and starch degradation products were removed with $50 \%$ methanol solution. The filtered product was dehydrated by washing with absolute ethanol and dried to give starch phosphate.

Furthermore, the use of extrusion can avoid problems such as time-consuming with efficiency and operation steps in the conventional process. At the same time, the high temperature, high pressure, and dry shear force in the extrusion process can also promote the phosphorylation of starch. Manoi and Rizvi [48] developed supercritical fluid extrusion (SCFX) using supercritical $\mathrm{CO}_{2}\left(\mathrm{SC}-\mathrm{CO}_{2}\right)$ as a foaming agent at a constant screw speed of $120 \mathrm{rpm}$, a temperature of $60-70^{\circ} \mathrm{C}$, and a pressure of $10-15 \mathrm{MPa}$. In general, physical extrusion is less expensive and more commercially viable than conventional oven heating.

\section{Effect of Different Starch Esters on Dough Properties}

Starch could dilute the gluten in the dough to an appropriate level, interweave with gluten, and absorb the water in the gluten by gelatinization. There are many deficiencies in the functionality of raw starch, and its quality has a direct impact on the quality of pasta. Starch esters are safe and reliable food additives and also dough quality improvers. The addition of different starch esters could improve the defect properties of the original starch [49]. By combining proteins, the gluten process characteristics, the dough processing performance, and gas holdability were heightened, and the improved pasta products were more glossy, elastic, and chewable. Different kinds and different amounts of esterified starch played different roles in improving dough quality. The results showed that adding starch acetate reduced the water absorption of the dough by $4 \%$, making the dough harder. The dough containing $20 \%$ starch acetate (DS: 0.03-0.04) lowered the gelatinization peak temperature and changed the endothermic enthalpy compared with the same amount of natural tapioca starch; thus, it could be applied in the preparation of noodles to delay aging [50]. Shukri et al. found the rheological difference between pure wheat flour dough and mixed powder dough containing 15\% phosphate cross-linked starch ester, the water absorption rate decreased from $64.3 \%$ to $62.9 \%$, the dough development time (DDT) was 2 times longer than the original flour, and the mixed tolerance index was positively correlated with the added amount. The wheat dough rich in phosphorylated starch had a significantly reduced ductility and tends to break faster than the control dough. In terms of finished products, steamed buns which are reinforced with cross-linked starch phosphate (15\% and 30\%) had significantly lower hardness, stickiness, and chewiness, while elasticity was not affected [51].

The quality of the dough during freezing could also be improved by adding starch esters. During the frozen storage of the dough and repeated cycles of freeze-thaw cycles, the surface moisture would be lost due to sublimation and the recrystallization of water and the formation of ice crystals will cause physical damage to the gluten structure, resulting in the weakening of the hydrophobic bonds $[52,53]$. The addition of starch acetate and cross-linked starch phosphate could effectively delay the aging of frozen dough and improve the quality of the dough or bread quality, and the starch ester with high degree of substitution delays the aging phenomenon more clearly [54]. Starch octenylsuccinate could also significantly improve the internal structure of frozen dough and alleviate the aging of starch. When the ice crystals in the dough gradually became larger in refrigeration, OSA starch amylopectin molecules could form hydrophilic and hydrophobic bonds with other components in the dough (natural starch, protein, water, and lipids), thereby strengthening the gluten network and avoiding ice crystals that disrupted the structure of the gluten network as well as the possible collapse and skin cracking of the frozen dough during thawing. Similarly, starch octenylsuccinate acted as a protein cryoprotectant to prevent denaturation of the dough protein at low temperatures that extend the shelf life of the dough.

There is a range of important technological properties of starch which could be esterified by biotechnological, physical, and chemical methods. Esterified starches may be used to replace wheat flour in traditional bakery at the level of $20 \%$, without deterioration of quality of final products. Their addition influences water absorption and rheological parameters of the dough, pasting characteristics of starch, and texture and staling of the obtained crumb. It allows to formulate recipes for bread with special, strictly controlled properties [50]. The application of esterified starches (acetylated distarch adipate and hydroxypropyl distarch phosphate) caused the increase in volume of the obtained gluten-free loaves, and the observed differences were statistically significant at the levels above $10 \%$. The changes were accompanied by modification of structural properties of bread crumb, e.g., a decrease of average cell size and an increase in their number. However, the addition of modified starch crumb structure became more elastic, which was revealed in the results of stress relaxation. A slight decrease in hardness and chewiness of the crumb was also observed on the day of baking, and its extent depended on the level of modified starch and was a little more pronounced in case of starch adipate [55]. 


\section{Expectation}

The preparation process and physicochemical properties of various starch esters have been studied in detail, but there are still many drawbacks at present. The esterification efficiency in chemical synthesis was still unsatisfied, and on the other hand, expensive cost and organic solvent which was harmful to environment and human health in the process was expected to be solved. With the rise of enzymatic synthesis last several years, the future process would be more environmentally friendly and efficient. At the same time, except single esterified starch, the composite modified starch has also received extensive attention. With the continuous improvement of the technology, esterified starch would have more development space in the fields of food, biomaterials, and other fields. The production technology would gradually mature and adapt to the trend of modern industrial production.

\section{Conflicts of Interest}

The authors declare that there are no conflicts of interest.

\section{Acknowledgments}

The authors would like to acknowledge NSFC for financial assistance under NSFC Research Contract nos. 31701636 and 31171789 and National key Research and Development program (no. 2016YFD0401302).

\section{References}

[1] D. Le Corre, J. Bras, and A. Dufresne, "Starch nanoparticles: a review," Biomacromolecules, vol. 11, no. 5, pp. 1139-1153, 2010.

[2] B. Kaur, F. Ariffin, R. Bhat, and A. Karim, "Progress in starch modification in the last decade," Food Hydrocolloids, vol. 26, no. 2, pp. 398-404, 2012.

[3] O. B. Wurzburg, Modified Starches: Properties and Uses, CRC Press, Inc., 2nd edition, 1987

[4] J. Singh, L. Kaur, and O. J. McCarthy, "Factors influencing the physico-chemical, morphological, thermal and rheological properties of some chemically modified starches for food applications-a review," Food Hydrocolloids, vol. 21, no. 1, pp. 1-22, 2007.

[5] Modified Starches, Food Additives (Uses Other than as Flavouring Agents), Database of Joint FAO/WHO Expert Committee on Food Additives (JECFA), http://apps3.fao.org/ jecfa/additive specs/docs/9/additive-0840.htm.

[6] Z. Chen, H. A. Schols, and A. G. J. Voragen, "Physicochemical properties of starches obtained from three varieties of Chinese sweet potatoes," Journal of Food Science, vol. 68, no. 2, pp. 431-437, 2003.

[7] S. G. Choi and W. L. Kerr, "Swelling characteristics of native and chemically modified wheat starches as a function of heating temperature and time," Starch-Stärke, vol. 56, no. 5, pp. 181-189, 2004.

[8] K. Morikawa and K. Nishinari, "Effects of granule size and size distribution on rheological behaviour of chemically modified potato starch," Journal of Food Science, vol. 67, no. 4, pp. 1388-1392, 2002.
[9] S. H. Koo, K. Y. Lee, and H. G. Lee, "Effect of cross-linking on the physicochemical and physiological properties of corn starch," Food Hydrocolloids, vol. 24, no. 6-7, pp. 619-625, 2010.

[10] Y. Lebenthal-Bendor, R. C. Theuer, A. Lebenthal, I. Tabi, and E. Lebenthal, "Malabsorption of modified food starch (acetylated distarch phosphate) in normal infants and in 8-24month-old toddlers with non-specific diarrhea, as influenced by sorbitol and fructose," Acta Paediatrica, vol. 90, no. 12, pp. 1368-1372, 2001.

[11] S. Mali and M. V. E. Grossmann, "Preparation of acetylated distarch adipates by extrusion," LWT-Food Science and Technology, vol. 34, no. 6, pp. 384-389, 2001.

[12] F. X. Luo, Q. Huang, X. Fu, L. X. Zhang, and S. J. Yu, "Preparation and characterisation of crosslinked waxy potato starch," Food Chemistry, vol. 115, no. 2, pp. 563-568, 2009.

[13] V. M. Acquarone and M. A. Rao, "Influence of sucrose on the rheology and granule size of cross-linked waxy maize starch dispersions heated at two temperatures," Carbohydate Polymers, vol. 51, no. 4, pp. 451-458, 2003.

[14] O. B. Wurzburg, Modified Starches: Properties and Uses, CRC Press, Inc., Boca Raton, FL, USA, 2000.

[15] R. Bhosale and R. Singhal, "Process optimization for the synthesis of octenyl succinyl derivative of waxy corn and amaranth starches," Carbohydrate Polymers, vol. 66, no. 4, pp. 521-527, 2006.

[16] T. Yoshimura, R. Yoshimura, C. Seki, and R. Fujioka, "Synthesis and characterization of biodegradable hydrogels based on starch and succinic anhydride," Carbohydrate Polymers, vol. 64, no. 2, pp. 345-349, 2006.

[17] H. J. Chung, S. E. Lee, J. A. Han, and S. T. Lim, "Physical properties of dry-heated octenyl succinylated waxy corn starches and its application in fat-reduced muffin," Journal of Cereal Science, vol. 52, no. 3, pp. 496-501, 2010.

[18] L. Altuna, M. L. Herrera, and M. L. Foresti, "Synthesis and characterization of octenyl succinic anhydride modified starches for food applications. A review of recent literature," Food Hydrocolloids, vol. 80, pp. 97-110, 2018.

[19] M. W. Rutenberg and D. Solarek, "Starch derivatives: production and uses," in Starch Chemistry and Technology, pp. 312-388, Academic Press, New York, NY, USA, 1984.

[20] J. Xu, C. W. Zhou, R. Z. Wang et al., "Lipase-coupling esterification of starch with octenyl succinic anhydride," Carbohydrate Polymers, vol. 87, no. 3, pp. 2137-2144, 2012.

[21] C. Wang, X. He, X. Fu, F. Luo, and Q. Huang, "High-speed shear effect on properties and octenylsuccinic anhydride modification of corn starch," Food Hydrocolloids, vol. 44, pp. 32-39, 2015.

[22] Z. G. Luo and Y. C. Shi, "Preparation of acetylated waxy, normal, and high-amylose maize starches with intermediate degrees of substitution in aqueous solution and their properties," Journal of Agricultural and Food Chemistry, vol. 60, no. 37, pp. 9468-9475, 2012.

[23] N. Singh, D. Chawla, and J. Singh, "Influence of acetic anhydride on physicochemical, morphological and thermal properties of corn and potato starch," Food Chemistry, vol. 86, no. 4, pp. 601-608, 2004.

[24] R. Colussi, S. L. M. E. Halal, V. Z. Pinto et al., "Acetylation of rice starch in an aqueous medium for use in food," LWT-Food Science and Technology, vol. 62, no. 2, pp. 1076-1082, 2015.

[25] M. V. Tupa, J. A. Á. Ramírez, A. Vázquez, and M. L. Foresti, "Organocatalytic acetylation of starch: effect of reaction conditions on DS and characterisation of esterified granules," Food Chemistry, vol. 170, pp. 295-302, 2015. 
[26] B. Volkert, A. Lehmann, T. Greco, and M. H. Nejad, “A comparison of different synthesis routes for starch acetates and the resulting mechanical properties," Carbohydrate Polymers, vol. 79, no. 3, pp. 571-577, 2010.

[27] R. Colussi, V. Z. Pinto, S. L. M. E. Halal et al., "Structural, morphological, and physicochemical properties of acetylated high-,medium-, and low-amylose rice starches," Carbohydrate Polymers, vol. 103, pp. 405-413, 2014.

[28] K. Zhao, B. Li, M. Xu et al., "Microwave pretreated esterification improved the substitution degree, structural and physicochemical properties of potato starch esters," LWTFood Science and Technology, vol. 90, pp. 116-123, 2018.

[29] J. Hong, R. Chen, X. A. Zeng, and Z. Han, "Effect of pulsed electric fields assisted acetylation on morphological,structural and functional characteristics of potato starch," Food Chemistry, vol. 192, pp. 15-24, 2016.

[30] E. M. Osman, R. L. Whistler, J. N. BeMiller, and E. F. Paschall, Starch in the Food Industry. Starch: Chemistry and Technology, Vol. 2, Academic Press, New York, NY, USA, 1967.

[31] F. F. Dias, H. K. Tekchandani, and D. Mehta, "Modified starches and their use by food industries," Indian Food Industry, vol. 16, no. 4, pp. 33-39, 1997.

[32] J. V. Tuschhoff, "Hydroxypropylated starches," in Modified Starches: Properties and Uses, O. B. Wurzburg, Ed., pp. 90-95, CRC Press, Boca Raton, FL, USA, 1987.

[33] S. Zhou, Y. Zhang, and W. Fan, "Effect of etherification and crosslinking on the functional properties of corn," Wuxi Qinggongye Xueyuan Xuebao, vol. 10, no. 1, pp. 31-40, 1991.

[34] M. N. Islam and B. M. N. M. Azemi, "Rheological properties of calcium treated hydroxypropyl rice starches," Starch-Stärke, vol. 49, no. 4, pp. 136-141, 1997.

[35] M. Wootton and X. Haryadi, "Effect of starch type and preparation conditions on substituent distribution in hydroxypropyl starches," Journal of Cereal Science, vol. 15, no. 2, pp. 181-184, 1992.

[36] M. Wootton and D. Mahdar, "Properties of starches from Australian wheats. Part 3: In vitro digestibility and hydroxypropyl derivatives," Starch-Stärke, vol. 45, no. 10, pp. 337-341, 1993.

[37] B. M. N. M. Azemi and M. Wootton, "Distribution of partial digestion products of hydroxypropyl derivatives of maize and high amylose maize starches," Starch-Stärke, vol. 46, no. 11, pp. 440-443, 1994.

[38] C. Perera and R. Hoover, "The reactivity of porcine pancreatic alpha-amylase towards native, defatted and heat-moisture treated potato starches before and after hydroxypropylation," Starch-Stärke, vol. 50, no. 5, pp. 206-213, 1998.

[39] R. Hoover, D. Hannonz, and F. W. Sosulski, "Effect of hydroxypropylation on thermal properties, starch digestibility and freeze thaw stability of field pea (Pisum sativum cv Trapper)," Starch-Stärke, vol. 40, no. 10, pp. 383-387, 1988.

[40] E. T. Hjermstad and L. C. Martin, "Etherifying starch granules in aliphatic ketone solvents," US Patent 3,135,739, 1964.

[41] H. Y. Kim, J. L. Jane, and B. Lamsal, "Hydroxypropylation improves film properties of high amylose corn starch," Industrial Crops and Products, vol. 95, pp. 175-183, 2017.

[42] A. L. Chaudhary, M. Miler, P. J. Torley, P. A. Sopade, and P. J. Hally, "Amylose content and chemical modification effects on the extrusion of thermoplastic starch from maize," Carbohydrate Polymers, vol. 74, no. 4, pp. 907-913, 2008.

[43] N. A. Landerito and Y. J. Wang, "Preparation and properties of starch phosphates using waxy, common, and high-amylose corn starches. II. Reactive extrusion method," Cereal Chemistry Journal, vol. 82, no. 3, pp. 271-276, 2005.

[44] R. Shukri and Y. C. Shi, "Structure and pasting properties of alkaline-treated phosphorylated cross-linked waxy maize starches," Food Chemistry, vol. 214, pp. 90-95, 2017.

[45] L. Passauer, H. Bender, and S. Fischer, "Synthesis and characterisation of starch phosphates," Carbohydrate Polymers, vol. 82, no. 3, pp. 809-814, 2010.

[46] R. L. Shogren, "Flocculation of kaolin by waxy maize starch phosphates," Carbohydrate Polymers, vol. 76, no. 4, pp. 639644, 2009.

[47] I. Przetaczek-Roznowska and T. Fortuna, "Effect of conditions of modification on thermal and rheological properties of phosphorylated pumpkin starch," International Journal of Biological Macromolecules, vol. 104, pp. 339-344, 2017.

[48] K. Manoi and S. S. H. Rizvi, "Physicochemical characteristics of phosphorylated cross-linked starch produced by reactive supercritical fluid extrusion," Carbohydrate Polymers, vol. 81, no. 3, pp. 687-694, 2010.

[49] N. Morita, T. Maeda, M. Miyazaki, M. Yamamori, H. Miura, and I. Ohtsuka, "Dough and baking properties of high-amlose and waxy wheat flours," Cereal Chemistry Journal, vol. 79, no. 4, pp. 491-495, 2002.

[50] M. Miyazaki, P. V. Hung, T. Maeda, and N. Morita, "Recent advances in application of modified starches for breadmaking," Trends in Food Science \& Technology, vol. 17, no. 11, pp. 591-599, 2006.

[51] F. S. A. Shukri, S. A. Refai, R. Shukri et al., "Dough rheology and physicochemical properties of steamed buns fortified with cross-linked rice starch," Bioactive Carbohydrates and Dietary Fibre, vol. 12, pp. 1-6, 2017.

[52] J. Eckardt, C. Öhgren, A. Alp et al., "Long-term frozen storage of wheat bread and dough e Effect of time, temperature and fibre on sensory quality, microstructure and state of water," Journal of Cereal Science, vol. 57, no. 1, pp. 125-133, 2013.

[53] M. Bhattacharya, T. M. Langstaff, and W. A. Berzonsky, "Effect of frozen storage and freeze-thaw cycles on the rheological and baking properties of frozen doughs," Food Research International, vol. 36, no. 4, pp. 365-372, 2003.

[54] M. Miyazaki, T. Maeda, and N. Morita, "Bread quality of frozen dough substituted with modified tapioca starches," European Food Research and Technology, vol. 227, no. 2, pp. 503-509, 2008.

[55] M. Witczak, L. Juszczak, R. Ziobro, and J. Korus, "Influence of modified starches on properties of gluten-free dough and bread. Part I: rheological and thermal properties of gluten-free dough," Food Hydrocolloids, vol. 28, no. 2, pp. 353-360, 2012. 


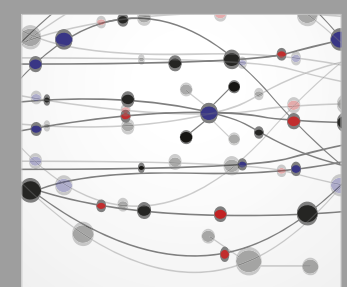

The Scientific World Journal
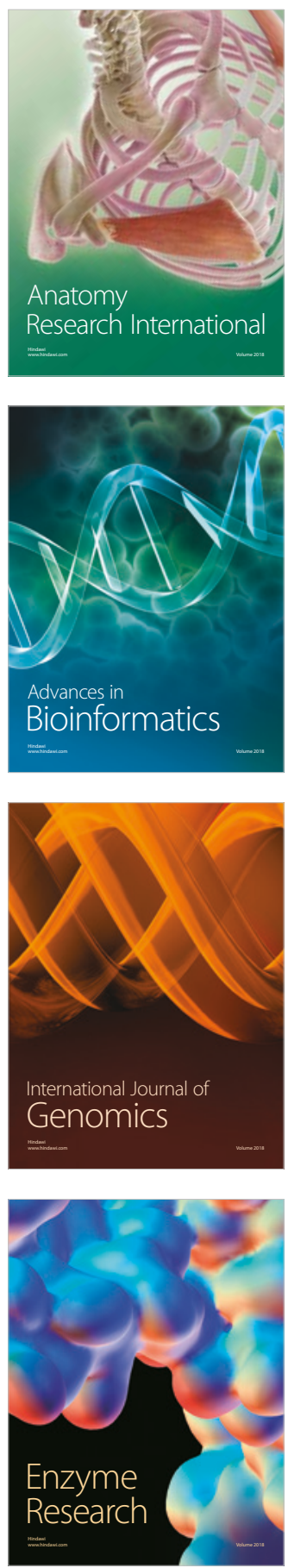
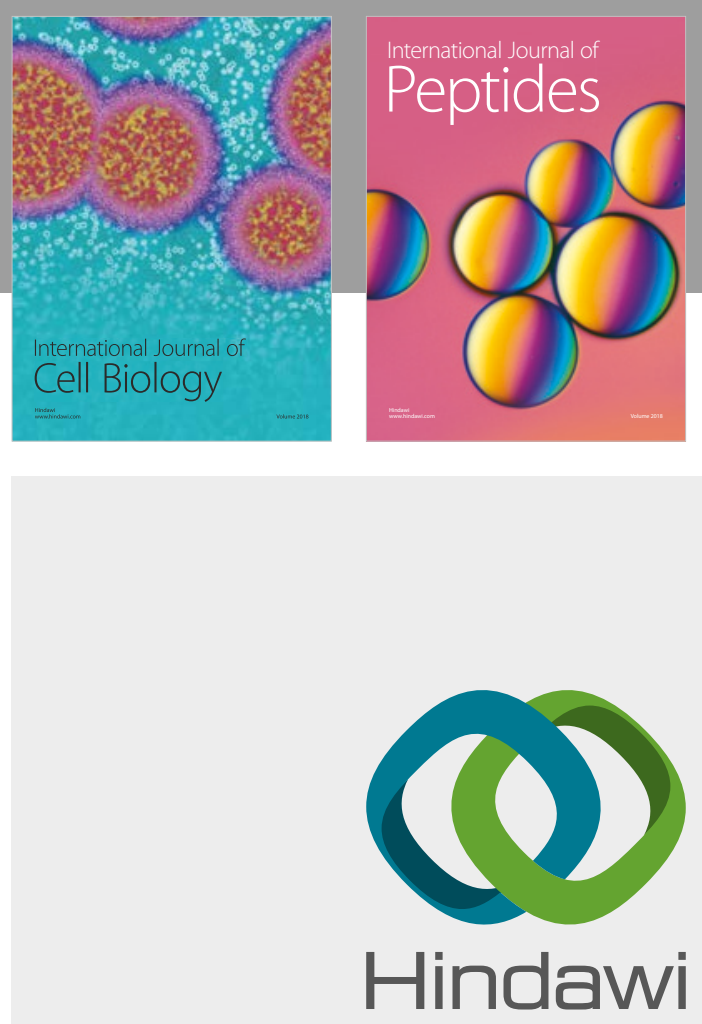

Submit your manuscripts at

www.hindawi.com
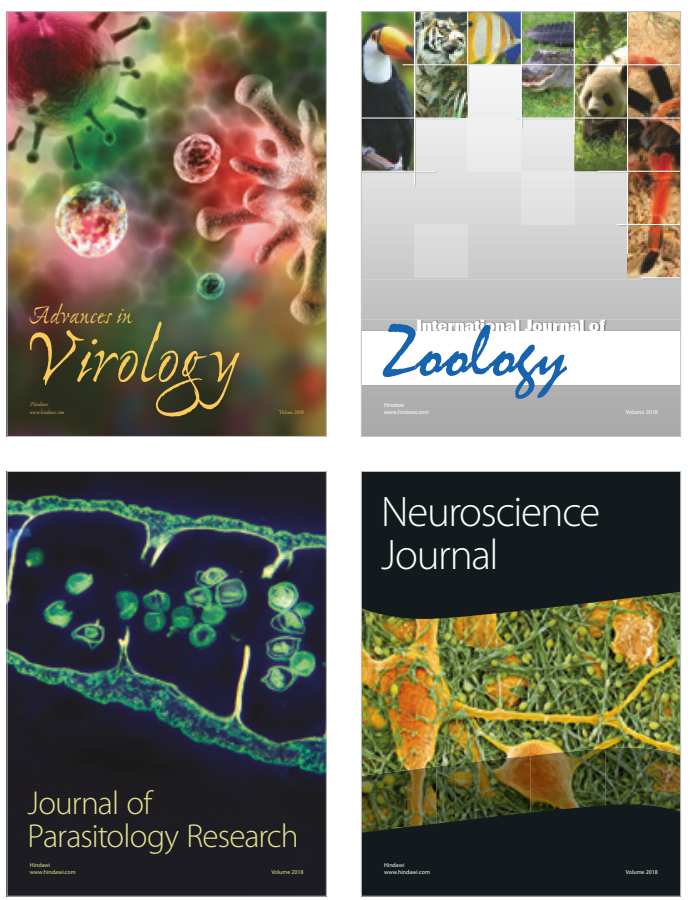
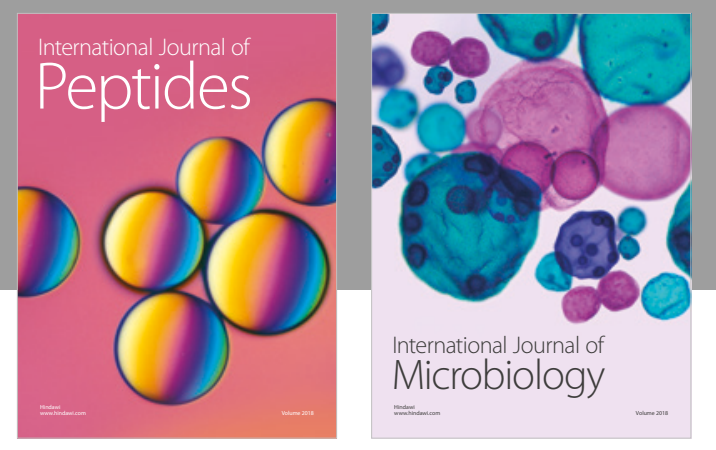

nternational Journal of Microbiology
Journal of
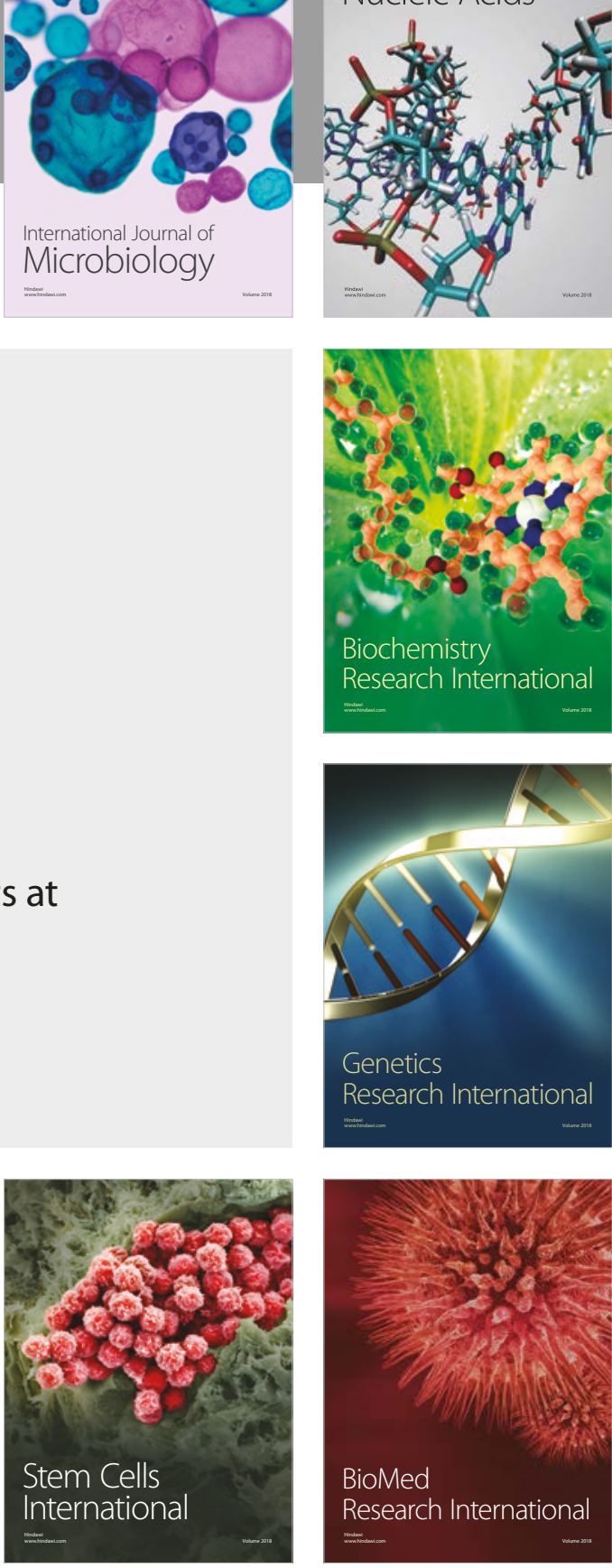
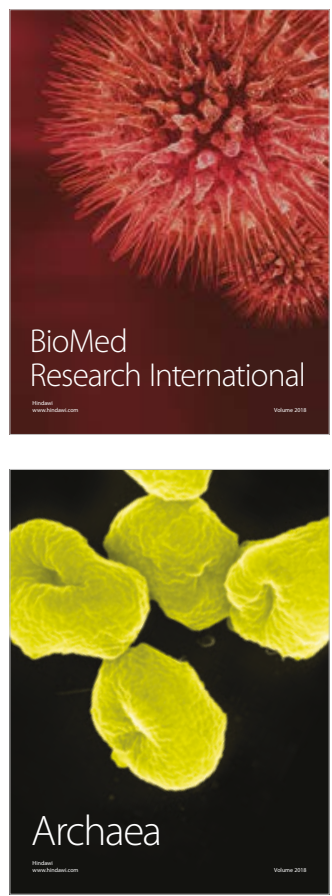